\title{
Enhancing nurses' knowledge and awareness about risk management: system design \\ G.M.A. Mostafa ${ }^{1}$
}

$$
\text { تحسين معارف وإدران محمد أحمد مصطفى الممرضات لإدارة المخاطر : تصميم النظام }
$$

الخلاصـة: إن إدارة المخاطر عملية يتم من خلالها التعرف على المخاطر المحتملة وتحليلها ومعالمتها

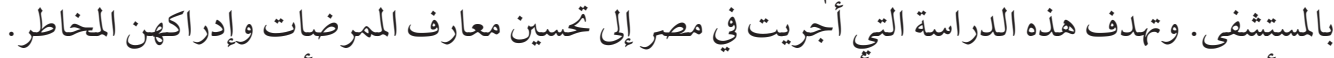

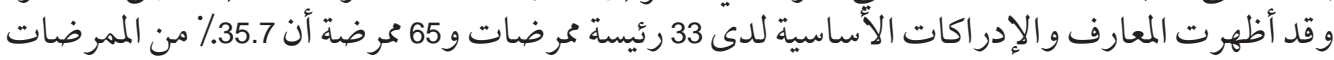

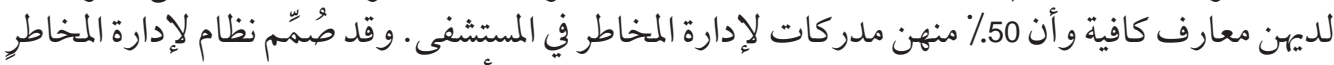

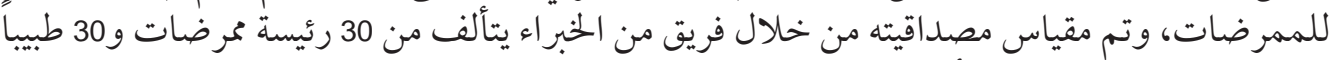

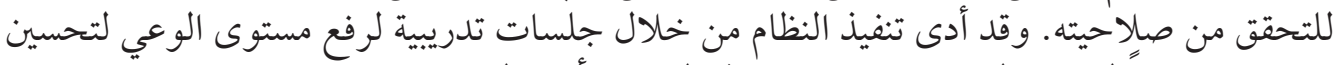

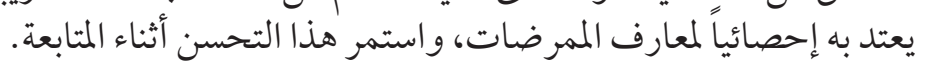

ABSTRACT Risk management is a process that identifies, analyses and treats potential hazards in a hospital. This study in Egypt aimed to enhance nurses' knowledge and awareness about risk management. Baseline knowledge and awareness of 33 nurse managers and 65 staff nurses showed that $35.7 \%$ of nurses had adequate knowledge and $50.0 \%$ were aware of the current risk management processes at the hospital. A nursing risk management system was designed and a jury group of 30 nursing leaders and 30 physicians validated the system. Implementation of the system through training sessions to raise awareness led to statistically significant improvements in nurses' knowledge, which persisted at follow-up.

Amélioration des connaissances des infirmiers sur la gestion des risques : conception d'un système

RÉSUMÉ La gestion des risques est un processus qui recense, analyse et traite les dangers potentiels dans un hôpital. Cette étude menée en Égypte visait à améliorer les connaissances des infirmiers en matière de gestion des risques. Les données de départ relatives à ces aspects recueillies auprès de 33 cadres infirmiers et 65 infirmiers principaux ont montré que $35,7 \%$ des infirmiers avaient des connaissances suffisantes et que 50,0\% étaient informés des processus de gestion des risques mis en œuvre à l'hôpital. Un système de gestion des risques infirmiers a été élaboré et une commission composée de 30 responsables infirmiers et de 30 médecins l'a validé. La mise en place du système grâce à des séances de formation a permis des améliorations statistiquement significatives des connaissances des infirmiers, qui se sont maintenues lors du suivi.

${ }^{1}$ Department of Nursing Administration, Faculty of Nursing, Helwan University, Cairo, Egypt (Correspondence to G.M.A. Mostafa: gehansaber40@yahoo.com).

Received: 27/12/06; accepted: 23/04/07

المجلة الصحية لشرق المتوسط، منظمة الصحة العالمية، المجلد الخامس عشر، العدد 0، 9 +. 


\section{Introduction}

Risk management in health care is a structured process for minimizing potential liability to health care providers, avoiding harm to patients, stabilizing health care providers' insurance costs and protecting hospitals from ruinous financial losses [1]. It consists of 3 interrelated areas: risk identification and loss prevention; loss reduction; and risk financing. To be most effective in the hospital setting, risk management involves a multidisciplinary and proactive approach [2].

The hospital risk management committee usually includes a physician as chairman, representatives from major medical and surgical departments, the nursing director, technical staff, representatives from the quality assessment department, the risk manager, one or more members of the governing body and hospital legal counsel. This committee reports to the hospital medical staff, governing body and administration and frequently serves as the primary source of ongoing education on loss prevention in a facility [3]. The responsibilities of the committee include the preparation of a written statement detailing the involvement of every department, monitoring all incidents related to patient care, recommending and implementing corrective action and preparing a risk management programme that is compliant with the Joint Commission on the Accreditation of Healthcare Organizations (JCAHO) and regulatory agencies [4].

The risk manager schedules meetings and prepares the agenda for the risk management committee, reviews incident reports daily, monitors data collection mechanisms, such as incident report summaries and, with the help of risk management committee members, develops staff education programmes [4]. Moreover, staff nurses should maintain an awareness of risk. According to Rowland and Rowland, "the chief nurse administrator should hold the administrative staff accountable for being familiar with risks in the environment through the use of risk management data collected by the hospital" [5].

In the current health care environment in Egypt, with increasing numbers of patients and a shortage of nursing staff, there is a high probability of physical or psychological harm to patients as a result of the health care provider's negligence. This could include patient falls, medication errors, product liability and environmental risks. Quality in health care begins with ensuring patient safety. Therefore, risk management tactics need to be developed and implemented to mitigate the effects of errors, to protect patients from risk and to help hospitals to achieve high quality care.

The present study in Egypt was designed to assess the knowledge and awareness of hospital nursing staff about risk management concepts; to use the assessment data to design and validate a nursing risk management system; and to determine the effect of implementation of a knowledge course about the system on nursing staff's knowledge.

\section{Methods}

\section{Research design}

A pre-post intervention study design was used. The pre-intervention was a crosssectional descriptive study to obtain baseline data on nurses' knowledge and awareness on which the intervention was based. The intervention was the design of a risk management system, its validation by a jury panel and training of nurses to raise awareness of the system. This was followed by post-intervention and follow-up assessments. 


\section{Setting}

The study was conducted in all inpatient units in the Medical Specialty Hospital, University of Mansoura, Egypt. The hospital consists of 3 floors with 100 beds. The distribution of nursing staff was 22 in the gastro-hepatology department, 29 in the diabetes/endocrine department, 17 in the geriatrics department and 30 in the cardiovascular department.

\section{Subjects}

To collect data on nurses' knowledge and awareness, all nursing staff in the study hospital were included in the study sample. Their ages ranged from 17 to 58 years. There were 33 nurse managers (1 matron, 1 assistant matron and 31 head nurses, all with a bachelor's degree in nursing) and 65 staff nurses (22 with a secondary nursing diploma, 41 a specialty diploma and 2 a technical institute diploma).

For assessing the design of the intervention, a 60-member jury group was composed of 30 nursing leaders and 30 physicians from Mansoura, Cairo, Zagazig and AlAzhar Universities. The nursing jury group included 15 nurse managers from hospitals (with a bachelor's degree) and 15 academic staff from the Faculty of Nursing (with a nursing doctorate). The physician group included 15 doctors from hospitals (4 with a bachelor's degree and 11 with a master's degree in medicine) and 15 academic staff from the Faculties of Medicine (all with doctorate degrees).

\section{Tools}

Three tools were used for data collection: an observation checklist, a risk management questionnaire and an opinion sheet.

\section{Observation checklist}

The observation checklist was developed by the researcher, guided by the literature
[6], to record which aspects of a risk management system were present in the study setting. It included 17 items to assess the presence of a risk management system and risk management committee, and aspects of medication administration forms and incident reporting.

\section{Risk management knowledge and awareness questionnaire}

A questionnaire was developed by the researcher, guided by the literature [6]. It aimed to determine the knowledge and awareness of nursing staff about risk management.

The knowledge section was designed to assess knowledge pre- and post-intervention. It had 4 parts: demographic data (age, nursing qualification, job position and department); knowledge about the definition and content of risk management systems and about incident reporting (25 multiple-choice questions); knowledge about medication errors (24 items); and knowledge about patients' falls and the associated risk factors/causes (20 questions). For the knowledge items, a correct response was scored 1 and incorrect 0 .

The awareness section aimed to help in designing a risk management system for the hospital. It consisted of items about awareness of the risk management committee, the medication administration form, the incident report form in the patient file and the general criteria of incident reporting (39 items). Responses were compared with the observation checklist. A response that was consistent with the observation was scored 1 and inconsistent 0 .

For each area of knowledge and awareness, the scores of the items were summed and the total divided by the number of items to give a mean score. These scores were converted into a percentage score. For each area of knowledge, knowledge was consid- 
ered satisfactory if the score was $\geq 60 \%$, and unsatisfactory if $<60 \%$. A nurse was considered to be aware if the awareness score was $\geq 60 \%$ and unaware if $<60 \%$.

\section{Opinion sheet}

The opinion sheet was developed by the researcher, guided by the literature [2,6]. It aimed to validate the risk management system that was designed for the study hospital. The jury members were asked to read the designed format of the system and express their agreement or disagreement with its content in terms of whether it appeared to reflect the concept the researcher intended or not. The tool consisted of 45 items: the general content of the proposed risk management system (2 items); its general objective (10 items); the tools of the evaluation system (4 items); the objectives of the process ( 7 items); the incident reporting system (17 items); and the procedures for incident reporting (5 items). The responses were agree/disagree, with comments and/or suggestions allowed.

\section{Validity and pilot testing}

The tools were translated into Arabic and tested for content validity through the expert opinions of 5 professors in nursing administration and 5 nurse managers in the hospital. Prior to data collection, the tools were pilottested on a group of 4 nurses in the study hospital to identify ambiguous questions. Accordingly, minor changes were made for a few unclear words. The reliability of the tools was also tested using Crombach alpha coefficient. For the questionnaire, it was 0.92 for the knowledge section and 0.90 for the awareness section.

\section{Data collection and intervention phases}

Official permission to collect the data for the study was obtained through letters from the Faculty of Nursing at Mansoura University to the hospital director and to the nursing director. Data were collected during 7 months from January 2006 to July 2006.

\section{Pre-intervention}

The pre-intervention knowledge and awareness questionnaires were used to collect baseline data. The methods of data collection were by interview for the questionnaire and by observation for the assessment sheet. The survey was carried out for the 14 units in the 3 floors in the study hospital: gastrohepatology (3 units), diabetes/endocrine and geriatrics (6 units) and cardiovascular (5 units).

The researcher met with the nursing director and distributed the questionnaire sheet with her participation. Then the researcher met with the nursing staff in the sample to explain the purpose of the study, assure them about confidentiality (forms were completed anonymously) and ask for verbal consent to participate. The researcher explained how to fill the risk management questionnaire. The sheets were distributed to the nursing staff in every department. Each sheet took 1-1.5 hours to fill.

\section{Intervention}

According to the assessment data that were collected from the pre-intervention observation and questionnaire forms, a risk management system was designed.

To assist in implementing the system a training course took place at the Medical Specialty Hospital, Mansoura University. Scheduling was done with the permission of the medical director and in coordination with the nursing director. The baseline knowledge course on risk management included an outline of the risk management system to enhance the knowledge and awareness of the nursing staff. 
The researcher also designed a documentation sheet related to the system and printed the 1000 medication cards, 28 incident report logbooks and 28 medication administration logbooks. These were distributed equally in the 14 units. The nursing staff was trained by the researcher on how to fill the sheet in their units during their daily activities. Thus, the first day of the course consisted of training on filling the sheet and the next day was to observe the nurses completing the sheets and then to put the logbook into the unit. Implementation was done sequentially in all units to minimize disruption to services.

\section{Post-intervention}

The knowledge questionnaire was filled again by participating nurses after the intervention and again after 3 months follow-up to assess the effect of the intervention on knowledge.

\section{Statistical analysis}

Data entry was done using Microsoft Excel 2000 software, while statistical analysis was done using SPSS, version 10.0. Data were presented using descriptive statistics in the form of frequencies and percentages for qualitative variables. Crombach alpha coefficient was used to assess the reliability of the developed tools through their internal consistency. Qualitative variables were compared using the chi-squared test. Statistical significance was set at $P$-value $<0.05$.

\section{Results}

\section{Pre-intervention: presence of risk management systems}

Table 1 describes the elements of risk management that were present in the different units of the study hospital. None of the units had a risk management system or a risk management committee in place. Also, none of the units had a medication trolley with drawers or an incident reporting logbook. However, in the medication administration form, patients' name, dose schedule, medication type and signature of the person in charge were fully recorded $(100.0 \%)$.

\section{Pre-intervention: knowledge and awareness}

The pre-intervention survey of knowledge and awareness about risk management among the sample of nurses showed that the highest percentage for knowledge (74.5\%) was about susceptibility to incidents (Table 2 ). The lowest percentage (7.1\%) was about the definition of risk management. Overall, slightly more than one-third of the nurses (35.7\%) had satisfactory knowledge about the different aspects of risk management.

As for awareness of risk management, it was highest for the medication administration form in the patient file $(96.9 \%)$. Conversely, only a minority of nurses $(13.3 \%)$ were aware of the general criteria of incident reporting. Overall, half of the nurses $(50.0 \%)$ were aware of these aspects of risk management procedures in the study hospital.

Table 3 presents the relation between pre-intervention course knowledge and awareness about risk management among nurses in the study sample. It indicates that $60.0 \%$ of the nursing staff with satisfactory knowledge were aware of risk management, compared with $44.4 \%$ of those with unsatisfactory knowledge. However, this difference was not statistically significant $(P=0.14)$.

\section{Intervention design}

Table 4 shows the agreement of the jury groups about the format and components of the proposed risk management system. The great majority of both groups $(96.7 \%)$ were 


\begin{tabular}{|c|c|c|c|c|c|c|}
\hline \multirow[t]{3}{*}{ Risk management item } & \multicolumn{6}{|c|}{ Items present in unit } \\
\hline & \multicolumn{2}{|c|}{$\begin{array}{c}\text { Gastro- } \\
\text { hepatology } \\
\text { unit }(n=3)\end{array}$} & \multicolumn{2}{|c|}{$\begin{array}{l}\text { Cardiovascular } \\
\text { unit }(n=5)\end{array}$} & \multicolumn{2}{|c|}{$\begin{array}{l}\text { Endocrine unit } \\
\qquad(n=6)\end{array}$} \\
\hline & No. & $\%$ & No. & $\%$ & No. & $\%$ \\
\hline Risk management system & 0 & 0 & 0 & 0 & 0 & 0 \\
\hline \multicolumn{7}{|l|}{$\begin{array}{l}\text { Medication administration form in patient } \\
\text { file with: }\end{array}$} \\
\hline Patient name & 3 & 100 & 5 & 100 & 6 & 100 \\
\hline Dose schedule & 3 & 100 & 5 & 100 & 6 & 100 \\
\hline Signature of person in charge & 3 & 100 & 5 & 100 & 6 & 100 \\
\hline Room number & 0 & 0 & 0 & 0 & 0 & 0 \\
\hline Medication type & 3 & 100 & 5 & 100 & 6 & 100 \\
\hline Doctor in charge & 0 & 0 & 1 & 20 & 1 & 17 \\
\hline $\begin{array}{l}\text { System of individual distribution of } \\
\text { medication }\end{array}$ & 0 & 0 & 0 & 0 & 2 & 33 \\
\hline Medication trolley & 0 & 0 & 0 & 0 & 1 & 17 \\
\hline $\begin{array}{l}\text { Medication trolley has drawers for drugs } \\
\text { Labelling of medication packages with: }\end{array}$ & 0 & 0 & 0 & 0 & 0 & 0 \\
\hline Patient name & 0 & 0 & 2 & 40 & 2 & 33 \\
\hline Room number & 0 & 0 & 0 & 0 & 0 & 0 \\
\hline Drug name & 0 & 0 & 2 & 40 & 2 & 33 \\
\hline Doctor in charge & 0 & 0 & 0 & 0 & 1 & 17 \\
\hline Incident reporting: & & & & & & \\
\hline Incident report logbook & 0 & 0 & 0 & 0 & 0 & 0 \\
\hline Incident report form in patient file & 0 & 0 & 0 & 0 & 0 & 0 \\
\hline
\end{tabular}

in agreement about the proposed system and its face validity. The lowest percentage of agreement among nursing staff was about the process objectives $(73.3 \%)$ and the objectives of incident reporting (73.3\%). Among physicians, the lowest percentage of agreement $(50.0 \%)$ was in relation to the components of the risk management system and its process objectives. Overall, all items were agreed upon by $50 \%$ or more of the jury members in the 2 groups.

\section{Post-intervention and follow up: knowledge}

Nurses' knowledge about risk management throughout the phases of the survey is sum- marized in Table 5. Statistically significant changes were seen in almost all areas, and in total knowledge. The highest postintervention improvements were related to the definition of risk management $(99.0 \%)$, incident notification $(98.0 \%)$ and incident reporting (100.0\%). Conversely, knowledge about the causes and types of incidents did not show any statistically significant improvements post-intervention.

At the follow-up, there were lower scores for most items compared with the post-intervention levels, except for incident susceptibility, risk of falls and age at risk of incidents, which increased by $99.0 \%$, $100.0 \%$ and $99.0 \%$ respectively. However, 


\begin{tabular}{lcc}
\hline \multicolumn{3}{l}{$\begin{array}{l}\text { Table } 2 \text { Pre-intervention course knowledge and awareness about risk } \\
\text { management among nurses in the study sample }(\boldsymbol{n}=\mathbf{9 8})\end{array}$} \\
\hline $\begin{array}{l}\text { Satisfactory knowledge/ } \\
\text { Knowledge/awareness item }\end{array}$ & No. \\
& & $\%$ \\
\hline Knowledge & 7 & 7.1 \\
Definition of risk & 32 & 32.7 \\
Risk management system & & \\
Incidents: & 31 & 31.6 \\
Notification & 24 & 24.5 \\
Reporting & 32 & 32.7 \\
Prevention & 15 & 15.3 \\
Causes & 16 & 16.3 \\
Types & 73 & 74.5 \\
Susceptibility & 43 & 43.9 \\
Risk of falls & 69 & 70.4 \\
Age at risk & 35 & 35.7 \\
Total knowledge & & \\
Awareness & 75 & 76.5 \\
Risk management system in hospital & 76 & 77.6 \\
Risk management committee in hospital & 95 & 96.9 \\
Medication administration form in patient file & 52 & 53.1 \\
System of individual distribution of medication & 65 & 66.3 \\
Medication trolley in different departments & 64 & 65.3 \\
Medication trolley has drawers for drugs & 32 & 32.7 \\
Labelling of medication packages & 41 & 41.8 \\
Incident report form in patient file & 13 & 13.3 \\
General criteria of incident reporting & 49 & 50.0 \\
Total awareness & &
\end{tabular}

the majority of items in the follow-up tests were statistically significantly higher than at the pre-intervention (baseline) levels. Overall, statistically significant improve- ments were revealed in total knowledge both at the post-intervention and follow-up tests $(P<0.001)$.

Table 3 Relation between pre-intervention course knowledge and awareness about risk management among nurses in the study sample

\begin{tabular}{|c|c|c|c|c|c|c|}
\hline \multirow[t]{3}{*}{ Awareness } & \multicolumn{4}{|c|}{ Knowledge } & \multirow[t]{3}{*}{$\chi^{2}$} & \multirow[t]{3}{*}{$P$-value } \\
\hline & \multicolumn{2}{|c|}{$\begin{array}{c}\text { Satisfactory } \\
(\geq 60 \%)(n=35)\end{array}$} & \multicolumn{2}{|c|}{$\begin{array}{c}\text { Unsatisfactory } \\
(<60 \%)(n=63)\end{array}$} & & \\
\hline & No. & $\%$ & No. & $\%$ & & \\
\hline Aware ( $\geq 60 \%)$ & 21 & 60.0 & 28 & 44.4 & & \\
\hline Unware $(<60 \%)$ & 14 & 40.0 & 35 & 55.6 & 2.18 & 0.14 \\
\hline
\end{tabular}

المجلة الصحية لشرق المتوسط، منظمة الصحة العالمية، المجلد الخامس عشر، العدد 0، 9. ب 
Table 4 Agreement of jury groups about the proposed system and components of the risk management system

\begin{tabular}{|c|c|c|c|c|}
\hline \multirow[t]{3}{*}{ Component } & \multicolumn{4}{|c|}{ Range of agreement (\%) } \\
\hline & \multicolumn{2}{|c|}{ Nurses $(n=30)$} & \multicolumn{2}{|c|}{ Physicians $(n=30)$} \\
\hline & Lowest & Highest & Lowest & Highest \\
\hline System face validity & 96.7 & 96.7 & 96.7 & 96.7 \\
\hline $\begin{array}{l}\text { Main elements of risk management system: clear, } \\
\text { suitable, applicable, scientific, measurable }\end{array}$ & 80.0 & 93.3 & 73.3 & 93.3 \\
\hline $\begin{array}{l}\text { Components of system: clear, suitable, applicable, } \\
\text { scientific, measurable }\end{array}$ & 76.7 & 86.7 & 50.0 & 83.3 \\
\hline $\begin{array}{l}\text { Pre-post-intervention evaluation tools: clear, } \\
\text { suitable, scientific, measurable }\end{array}$ & 76.7 & 86.7 & 53.3 & 83.3 \\
\hline $\begin{array}{l}\text { Process objectives: clear, suitable, applicable, } \\
\text { scientific, measurable, sequential }\end{array}$ & 73.3 & 93.3 & 50.0 & 90.0 \\
\hline Proposed system face validity & 93.3 & 93.3 & 76.7 & 76.7 \\
\hline Proposed incident reporting: clear, comprehensive & 90.0 & 93.3 & 83.3 & 83.3 \\
\hline $\begin{array}{l}\text { Objectives of proposed incident reporting: clear, } \\
\text { suitable, applicable, scientific, measurable, } \\
\text { sequential }\end{array}$ & 73.3 & 93.3 & 63.3 & 90.0 \\
\hline $\begin{array}{l}\text { Components of proposed incident reporting: } \\
\text { clear, suitable, applicable, scientific, measurable, } \\
\text { sequential }\end{array}$ & 83.3 & 96.7 & 63.3 & 93.3 \\
\hline $\begin{array}{l}\text { Criteria of proposed incident reporting: clear, } \\
\text { suitable, scientific }\end{array}$ & 80.0 & 93.3 & 80.0 & 96.7 \\
\hline $\begin{array}{l}\text { Procedures in case of an incident: clear, suitable, } \\
\text { applicable, measurable }\end{array}$ & 80.0 & 96.7 & 60.0 & 80.0 \\
\hline Proposed system can be applied in other hospitals & 83.3 & 83.3 & 60.0 & 60.0 \\
\hline
\end{tabular}

Table 5 Baseline knowledge course implementation about risk management among nurses in the study sample throughout the study phases

\begin{tabular}{|c|c|c|c|c|c|c|c|c|c|c|}
\hline \multirow[t]{3}{*}{ Knowledge item } & \multicolumn{6}{|c|}{ Satisfactory score ( $\geq 60 \%)$} & \multirow{2}{*}{\multicolumn{2}{|c|}{$\begin{array}{l}\text { Between pre- and } \\
\text { post-intervention }\end{array}$}} & \multirow{2}{*}{\multicolumn{2}{|c|}{$\begin{array}{c}\text { Between } \\
\text { pre-intervention } \\
\text { and follow-up }\end{array}$}} \\
\hline & \multicolumn{2}{|c|}{$\begin{array}{c}\text { Pre- } \\
\text { intervention } \\
(n=98)\end{array}$} & \multicolumn{2}{|c|}{$\begin{array}{l}\text { Post- } \\
\text { intervention } \\
(n=98)\end{array}$} & \multicolumn{2}{|c|}{$\begin{array}{l}\text { Follow-up } \\
(n=98)\end{array}$} & & & & \\
\hline & No. & $\%$ & No. & $\%$ & No. & $\%$ & $\chi^{2}$ & $P$-value & $\chi^{2}$ & $P$-value \\
\hline Definition of risk & 7 & 7.1 & 97 & 99.0 & 68 & 69.4 & 165.93 & $<0.001$ & 80.37 & $<0.001$ \\
\hline $\begin{array}{l}\text { Risk management } \\
\text { system } \\
\text { Incidents: }\end{array}$ & 32 & 32.7 & 96 & 98.0 & 87 & 88.8 & 92.24 & $<0.001$ & 64.71 & $<0.001$ \\
\hline Notification & 31 & 31.6 & 96 & 98.0 & 72 & 73.5 & 94 & $<0$. & 34.40 & $<0.001$ \\
\hline Reporting & 24 & 24.5 & 98 & 100.0 & 85 & 86.7 & 118.89 & $<0.001$ & 7.91 & $<0.001$ \\
\hline Prevention & 32 & 32.7 & 90 & 91.8 & 77 & 21.4 & 73.03 & $<0.001$ & 41.85 & $<0.001$ \\
\hline Causes & 15 & 15.3 & 15 & 15.3 & 14 & 14.3 & - & - & 0.04 & 0.84 \\
\hline Types & 16 & 16.3 & 17 & 17.3 & 6 & 6.1 & 0.04 & 0.85 & 5.12 & 0.02 \\
\hline Susceptibility & 73 & 74.5 & 89 & 90.8 & 97 & 99.0 & 9.11 & 0.003 & 25.54 & $<0.001$ \\
\hline Risk of falls & 43 & 43.9 & 78 & 79.6 & 98 & 100.0 & 26.46 & $<0.001$ & 76.45 & $<0.001$ \\
\hline Age at risk & 69 & 70.4 & 88 & 89.8 & 97 & 99.0 & 11.56 & $<0.001$ & 30.86 & $<0.001$ \\
\hline Total & 35 & 35.7 & 98 & 100.0 & 98 & 100.0 & 92.84 & $<0.001$ & 92.84 & $<0.001$ \\
\hline
\end{tabular}




\section{Discussion}

Risk management is a process that identifies analyses and treats potential hazards within a given setting [7]. The risk management programme of a hospital is designed to "enhance the safety of patients, visitors and employees and minimize the financial losses through risk detection, evaluation and prevention" [8].

None of the studied departments in this hospital had a risk management system or risk management committee in place. There were deficiencies in the medication trolley and drawers for drugs and there were no incident reporting logbooks or forms in patients' files. However, medication administration forms were correctly filled with patient's name, dose schedule, signature of the person in charge and medication type.

These findings reflect some major potential problems for the hospital; the lack of a formal risk management system increases the probability of incidents both for patients and hospital. As stated by Nolan, a risk management system is "designed to help prevent errors, to make them detectable so they can be intercepted, and to provide means of mitigation if they are not intercepted" [9].

Only about one-third of the nurses had satisfactory knowledge about risk management and only half of them were aware about the concept. Even worse, only very small proportions were aware about the general criteria of incident reporting. Youngberg has emphasized that the reporting of incidents is a vital element of the risk management and quality assurance process in a health care setting [10].

A high incidence of patient falls in hospital is a major concern in any health system. Falls not only lead to pain, discomfort and fear for patients if they are injured, but can increase the duration of hospital stay [11].
According to the present study, nurses' knowledge about the causes of patient falls was low before implementation of the new system. This is an alarming finding since a lack of knowledge about the risk factors associated with falls would not allow for prevention or mitigation of the harm caused by these incidents. Furthermore, nurses' knowledge about the causes of incidents remained low throughout the phases of the present study. This needs to be given more consideration since a high incidence of patient falls in a hospital setting is a major concern in any health system. Therefore, incident reporting is important for nurses to be familiar with the hospital policy about their responsibilities and obligations. It gains a special importance if they are involved personally in an incident that results in or has the potential to harm patients, employees or visitors [12].

The lack of a risk management system in the study hospital, and the low levels of knowledge and awareness of risk management among nurses, point to the importance of designing a risk management system and training nurses on its application. For this hospital, a system was developed based on the needs assessment done at the baseline of the study. The increased awareness and knowledge of nurses about risk management shown in this study would ultimately have a positive impact on their performance.

The findings are in agreement with Brush, who also designed a system to reduce medication administration errors and emphasized the importance of knowledge of the risks associated with medication [13]. That study showed statistically significant reductions in the rates of medication errors and documenting errors following implementation of a training programme, which is a key element for risk prevention. 


\section{Conclusion}

Knowledge and awareness of the study nurses about risk management was generally very low at baseline. A risk management system was designed and validated, including a course for nurses. After implementation of the course, knowledge scores significantly improved and this was retained during the follow-up period.

\section{Recommendations}

Based on the findings of this study, it is recommended that the risk management system designed be followed by medical and nursing directors, with identification of the members of a risk management committee and a risk manager, and coordination between the quality assurance department and risk manager. Annual updating of the risk management system is essential. Routine reporting of incidents should be performed as a daily activity and special rewards should be given to nursing staff who report incidents, to motivate them towards incident reporting as a means of risk identification and prevention rather than punishment.

\section{References}

1. Montgomery B. Riskmanagement. Chapel Hill, North Carolina, Chapel Hill TrainingOutreach Project, ARCH National Legal Resource Center, 2002:1-3 (Arch Fact Sheet No. 17) (http://www.archrespite. org/archfs17.htm, accessed 5 December 2008).

2. Risk management handbook. New Haven Connecticut, Yale-New Haven Hospital and Yale School of Medicine, 1997:4-34.

3. Swansburg RC, Swansburg RJ. Introduction to management and leadership for nurse managers, 3rd ed. London, Boston, Jones and Bartlett Publishers, 2000:607-8.

4. Sullivan EJ, Decker P. Effective leadership and management in nursing, 4th ed. California, Addison-Wesely, 1997:15666.

5. Rowland HS, Rowland BL, eds. Nursing administration handbook, 4th ed. Gettysberg, Maryland, Aspen, 1994:9-41.

6. Sullivan EJ, Decker P. Effective management in nursing, 2nd ed. New York, Addison-Weseley, 1988:499-512.

7. Yoder-Wise PS. Leading and managing in nursing. St Louis, Missouri, Mosby Year Book, 1997:48, 200.
8. Perkins S. Risk management program [online article]. State University of New York Upstate Medical University (http:// www.upstate.edu/uha/risk/program.php, accessed 11 December 2008).

9. Nolan TW. System changes to improve patient safety. British medical journal, 2000, 320:771-3.

10. Youngberg BJ. Essentials of hospital risk management, 1st ed. Gettysberg, Maryland, Aspen Publication, 1990:41-195.

11 Kerzman $\mathrm{H}$ et al. Nursing and health care management and policy. Characteristics of falls in hospitalized patients. Journal of advanced nursing, 2004, 47(2):223-9.

12. Taylor C, Lillis C, Le Mone P. Fundamentals of nursing: the art and science of nursing care, 3rd ed. Philadelphia, JB Lippincott, 2001:524-7.

13. Brush K. Upgrading systems design to reduce medication administration errors. Clinical nurse specialist, 2003 17(1):15-6. 